\title{
Financial crises and volatility spillovers among emerging European equity markets
}

\author{
Ugur Ergun a*, Zehra Mahmutović a \\ a Management Department, Faculty of Economics, International Burch University, BIH \\ *Corresponding author's email: uergun@ibu.edu.ba
}

\author{
H I G H L I G H T S: \\ 1. We study the effect of current financial crisis on equity market returns of Balkan transition economies. \\ 2. The study employed generalized autoregressive conditional heteroscedasticity model for daily data spanning from 2006 \\ to 2012. \\ 3. Result suggests that volatility transmission take place from Bosnian and Croatian stock markets to Serbian stock market
}

\begin{tabular}{|c|c|}
\hline Article History & ABSTRACT \\
\hline Received: 20-05-2014 & Financial crisis not only have statistically but also economically significant impact on \\
\hline Accepted: 03-08-2014 & global equity market returns. This study analyzes whether current financial crisis affect the \\
\hline Available online: $30-08-2014$ & $\begin{array}{l}\text { equity market returns of Balkan transition economies and what is the extent of such } \\
\text { impact by employing Generalized Autoregressive Conditional Heteroscedasticity model is }\end{array}$ \\
\hline Keywords: & employed on daily data spans from 2006 to 2012 for three transition economies which are \\
\hline $\begin{array}{l}\text { Balkan transition economies; } \\
\text { GARCH (1.1); }\end{array}$ & $\begin{array}{l}\text { Bosnia-Herzegovina, Croatia and Serbia. Empirical result indicates that volatility of Serbian } \\
\text { stock price is influenced by the volatility of Bosnian and Croatian stock prices. There is one }\end{array}$ \\
\hline Equity markets; & way volatility transmission from Bosnian and Croatian stock markets to Serbian stock \\
\hline Volatility spillover. & $\begin{array}{l}\text { market. High degree of volatility is observed in the stock markets during latest financial } \\
\text { crises. }\end{array}$ \\
\hline
\end{tabular}

JEL Classification: C32; C58; G11; F36. DOI: http://dx.doi.org/10.18533/jefs.v2i04.140

(C) 2014 The Authors. This is an open access article under the terms of the Creative Commons Attribution License 4.0, which allows use, distribution and reproduction in any medium, provided the original work is properly cited.

\subsection{Introduction}

The global economic crisis brings drop in economic activity, illiquidity of real sector, the financing problems of current income, growth and development of companies, depressed consumer spending and aggregate demand, and an enormous increase in the unemployment rate. There is almost no economic sector which was not affected by the emerging market crisis. In today's global world crisis are easily transferred from one market to another. The intensity of its transmission depends on the economic strength of countries in which it originally emerged. Since the U.S. is still economically strongest country in the world, its impact on the world's economy is largest, and the crisis that emerged in U.S. in 1929. ("Great depression."), quickly spread to European and Asian markets as well. As time progresses, the right size and dimension of this crisis became visible, and this U.S. crisis actually demonstrated how interconnected markets, in fact, are. So that the market crisis is not only retained as a local event, rather it takes the global state. A financial crisis can thus be defined as an ongoing issue which brings there cession into many countries, and causes a downward flow into major stock indexes. In 1997, Asian financial crisis emerged. As a major shock, it had a strong influence on investors in emerging markets. Not only were there significant losses on investments, but also many investors had come to believe that rapid and relatively steady economic growth in the region was the norm and foresaw only mild market setbacks. The Asian crisis was followed by the Russian crisis in 1998, and several others. In the period of 2008-2012 global financial crisis known as "Great recession," has took 
place and is considered by many economists to be the worst financial crisis since the "Great depression" in U.S. The financial crisis has caused the emerging and developing economies to replace advanced economies to lead global economic growth. The mentioned crisis taught us that the confidence of financial market, ones it is shattered, it cannot be easily recovered. The latest analysis of the global financial and economic crisis, are including the possibility that the crisis has touched the bottom, and the worst is behind us, but do not exclude the fact that the full recovery of the world economy could take many years.

The economy of Bosnia and Herzegovina was in structural crisis before the economic crisis, due to its lack of planned development, incompetent government structures, and political interference in economic decision making. The global crisis has just "pulled back the veils" hiding our domestic crisis while opening a large number of other problems, as in other countries in transition. Despite being one of the world's fastest growing countries, Turkey is now facing a number of economic challenges, as a result, of the global economic downturn. The rest of this paper is focusing on the emerging market crisis which started in 2008 and is still present, and how this crisis affects the equity markets of developing countries such Bosnia and Herzegovina, and Turkey are.

The contribution of this study is twofold. At first we conduct an analysis covering old Yugoslavian transition economies focusing on the Croatia, Serbia and Bosnia-Herzegovina; later we employ the GARCH (1.1) to examine volatility spillover and transmission among stock markets of those three countries. At last we analyze the volatility structure of the selected countries 'stock markets before and after the latest world financial crises.

The remainder of this study is structured as follows: Section 2 presents a literature review. Section 3 presents the data and methodology employed in the empirical analysis. Section 4 gives the empirical result, whereas the section 5 concludes.

\section{$2.0 \quad$ Literature review}

The global economy and deregulated financial system are once again in crisis, and equity market is experiencing the lowest level in the past 70 years. "Rating agencies might add instability to financial markets in emerging economies, is the conclusion drawn from recent research about emerging market instability" (Kaminsky \& Schmukler, 2002). Although with the globalization effect, in which stock markets are expected to show uniform responses to shocks, the degree of stock market reactions to such shocks differs from one region to another, depending on the level of integration with the international economy (Nikkinen et al., 2008).

While financial crises are not a new phenomenon the current financial crisis differs from many of the previously studied crises in that it is both severe and global. It is well-documented that international capital markets react, in terms of returns and volatility, quickly and simultaneously to major events such as the crash of 1987 and the Asian crises in 1997. However, the timing and magnitude of changes in stock returns and volatility differ across markets around the world (Roll, 1988). The central message from the findings conducted by Samarakoon (2011) is that emerging markets have large normal sensitivities to U.S. shocks, and large declines in stock prices in these markets reflected these dependencies rather than contagion. The findings underline the importance of emerging markets as drivers to global asset price developments in recent years (Sáez, Fratzscher, \& Thimann, 2009).

The results of IMF study conducted in 2008 and covering 30 countries indicate that emerging market equity prices are influenced by changes in global financial conditions, such as liquidity, credit and market risks, as well as growth and exchange rate expectations. Therefore, global factors constitute a significant channel for spillovers when the international economic environment changes. A number of past financial studies deal with financial market linkages and shock contagion effects between mature and emerging equity markets (e.g. Ratanapakorn and Sharma, 2002; Bessler and Yang, 2003; Chaudhuri and Wu, 2003; Wong and Vlaar, 2003; Syriopoulos, 2004). Summarizing the earlier empirical findings, it can be postulated that the medium to long-term dynamic behavior of the Balkan equity markets can potentially be affected by co-movements and volatility in leading mature, developed equity markets. Nevertheless, the Balkan equity markets have been neglected, and empirical research remains thin on this region (Samitas et al., 2007). Some past studies indicate that emerging stock market behavior increasingly depends on mature stock market volatility swings (e.g. Phylaktis and Ravazzolo, 2002; Swanson, 2003; Yang et al., 2006; Syriopoulos, 2007). There is general agreement that the recent global financial crisis raised the costs and constraints in the financial sector in providing working capital, pre-shipment export finance, export credit insurance and insurance of letters of credit for international trade (Uygur; 2010). The global recovery remains fragile and uneven-sluggish in advanced countries, much stronger in emerging and developing countries. The recent crisis has come to Turkey rather late, but it hit hard swiftly (Ercan, Taymaz \& Yeldan; 2010). Bosnia and Herzegovina has been facing the difficult challenge of dealing with the legacies of the crisis and its past unsustainable policies while not hurting the recovery. The most widely applied models in situations where volatility of returns is central issue are ARCH (Engle, 1982) and a generalization of Engels's model known as GARCH introduced by Bollerslev (1986). 


\subsection{Data and methodology}

\subsection{Data}

To investigate the issue and to analyze the relationship among equity returns and emerging financial crisis this study uses daily equity returns of SASE (Bosnia and Herzegovina), Serbia (BELEX) and Croatia (CROBEX) for the period of 2005 -2012. This data has been applied to estimate the volatility transmission among the selected Balkan countries 'equity returns and the impact of financial crises on the volatility of selected equity returns.

\subsection{Generalized autoregressive conditional heteroscedasticity (GARCH)}

With the aim of contributing to the development of macroeconomics rational expectations, Professor Robert F. Engle in 1982 in an article has introduced and defined the term ARCH model. The term ARCH stands for autoregressive (depending on its past), conditional, and heteroscedasticity (non-constant variance). By "conditional", it is meant that likelihood is computed based on an estimated set of priming values for the squared innovations $\left(\varepsilon_{t}{ }^{2}\right)$ and the variances $\left(\sigma_{t}{ }^{2}\right)$. This means that ARCH model allows the current conditional variance to a function of the past squared error terms. Because of his contribution Engle was considered as the pioneer of the financial econometrics.

The first application of ARCH was in a study of inflation rates (Engle, 1982), and thereafter a variety of parametric and nonparametric specifications of autoregressive conditional heteroscedasticity have been proposed. ARCH models seek to estimate the time-dependent volatility as a function of observed prior volatility. The original ARCH model modeled the variance of disturbances as a linear function of lagged values and provides a framework of analysis and development of time series models of volatility. The ARCH model allows the variance of the error to vary over time, in contrast to the standard time series regression models where the variance is assumed to be constant.

The ARCH model can be written as:

$$
\begin{aligned}
& y_{t}=\mu_{t}+\sigma_{t} \varepsilon_{t} \\
& \mu_{t}=\mu \\
& \sigma_{t}^{2}=\alpha_{0}+\sum_{i=1}^{q} \alpha_{i} \alpha_{t-i}^{2}
\end{aligned}
$$

$\alpha_{t}=\sigma_{t} \varepsilon_{t}$

where $\varepsilon_{t}$ is a sequence of independent and identically distributed random variables with mean zero and variance 1 ; $\alpha_{0}>0, \alpha_{i} \geq 0$, for i $>0$.

From the structure of the ARCH model, it can be concluded that if there is a large shock in previous periods, in other words if there is a large variance in previous periods, it makes the present period's variance higher. It means that large shocks tend to follow by another large shock. This property of ARCH stands for the volatility clustering in financial time series. As the ARCH models are used to model the volatility, they are also used to understand whether and to what extent the volatility is transmitted across markets. The basic ARCH model has been extended in several ways; in 1986, Bollerslev generalized the autoregressive conditional heteroscedasticity model, and this GARCH is the most influential and widely-used extension of ARCH.

Measuring the relationship between variables at various points in time, rather than using a single correlation coefficient over the entire sample period, provides information on the evolution of the relationship over time. The methodology applied in this paper is GARCH (1.1) modeling, which is widely applied method for analyzing data at different.

The (1.1) in GARCH (1.1) model in Eq. (3.2) refers to the presence of a first-order GARCH term and a first-order ARCH term

$$
\begin{aligned}
& y_{t}=\beta x_{t}+\delta \sigma_{t}^{2}+\varepsilon_{t} \ldots \ldots . \\
& \varepsilon_{t-1}^{2} \quad 0+\alpha_{i} \varepsilon_{t-1}^{2}+\beta_{1} \sigma_{t-1}^{2} \ldots \\
& \sigma_{t-1}^{2}
\end{aligned}
$$


News about volatility from the previous period, measured as the lag of the squared residual from the mean equation (ARCH term) last periods forecast variance (GARCH term)

\subsection{Empirical results}

In order to evaluate volatility spillovers among three Balkan transition countries stock market return we form three variance equation model as follows;

$$
\begin{aligned}
& \mathrm{y}_{\mathrm{t}}=\beta \mathrm{x}_{\mathrm{t}}+\delta \sigma_{\mathrm{t}}^{2}+\varepsilon_{\mathrm{t}} \\
& \sigma_{\mathrm{t}}^{2}(\mathrm{BELEX})=\omega_{1}+\alpha_{1} \varepsilon_{\mathrm{t}-1}^{2}+\beta_{1} \sigma_{\mathrm{t}-1}^{2}+\beta_{2} \mathrm{CROBEX}+\beta_{3} \mathrm{SASE} . \\
& \text { Modl } 01 \\
& \sigma_{\mathrm{t}}^{2}(\mathrm{SASE})=\omega_{2}+\alpha_{2} \varepsilon_{\mathrm{t}-1}^{2}+\beta_{4} \sigma_{\mathrm{t}-1}^{2}+\beta_{5} \mathrm{CROBEX}+\beta_{6} \mathrm{BELEX} \\
& \text { Mode 02......(3.4) } \\
& \sigma_{\mathrm{t}}^{2}(\mathrm{CROBEX})=\omega_{3}+\alpha_{3} \varepsilon_{\mathrm{t}-1}^{2}+\beta_{7} \sigma_{\mathrm{t}-1}^{2}+\beta_{8} \mathrm{SASE}+\beta_{9} \text { BELEX ...........Mdel } 03 .
\end{aligned}
$$

Table shows the variance equation estimation results for three models. In all three models, stock market's volatility is being influenced by their past volatility. Significant ARCH coefficient in the variance equation implies that previous day's stock market return information about volatility is an important factor in defining today's market return volatility. It means that all three-stock market's return volatility is influenced by its own shocks which are

\begin{tabular}{|c|c|c|c|}
\hline \multicolumn{4}{|c|}{ Table GARCH (1.1) Estimation Result } \\
\hline Variables & Model 01 & Model 02 & Model 03 \\
\hline \multirow[t]{2}{*}{$\mathrm{C}$} & $4.50 \mathrm{E}-07$ & 0.00000257 & 0.00000339 \\
\hline & $(0.0003)^{*}$ & $(0.0000)^{*}$ & $(0.0015)^{*}$ \\
\hline \multirow[t]{2}{*}{$\mathrm{ARCH}$} & 0.01837 & 0.132604 & 0.107567 \\
\hline & $(0.0000)^{*}$ & $(0.0000)^{*}$ & $(0.0000)^{*}$ \\
\hline \multirow[t]{2}{*}{ GARCH } & 0.707029 & 0.857954 & 0.884762 \\
\hline & $(0.0000)^{*}$ & $(0.0000)^{*}$ & $(0.0000)^{*}$ \\
\hline \multirow[t]{2}{*}{ CROATIA } & 0.0000791 & 0.0000557 & \\
\hline & $(0.0204)^{*}$ & $(0.5095)$ & \\
\hline \multirow[t]{2}{*}{ BIH } & -0.000158 & & 0.0000761 \\
\hline & $(0.0338)^{*}$ & & $(0.4683)$ \\
\hline \multirow[t]{2}{*}{ SERBIA } & & -0.0000201 & 0.000125 \\
\hline & & $(0.7751)$ & $(0.2563)$ \\
\hline
\end{tabular}
ARCH and GARCH factors.

Furthermore, the result from the first model shows that Serbian stock market (BELEX) volatility is being influenced by Bosnian and Croatian stock market returns. In the second and third model outside shocks are not significant. Bosnian stock market and Croatian stock market is not being influenced by the outside shock from two neighbor countries.

In the second model, Croatian and Serbian stock market return is not significant meaning that volatility in CROBEX and BELEX does not transmit to SASE. In the third model also BELEX and SASE is not significant meaning that there is no volatility transmission from those markets to Croatian stock market. We can conclude that unlike Croatian and Bosnian stock markets, Serbian stock market volatility is influenced by the Croatian and Bosnian stock market volatility. 


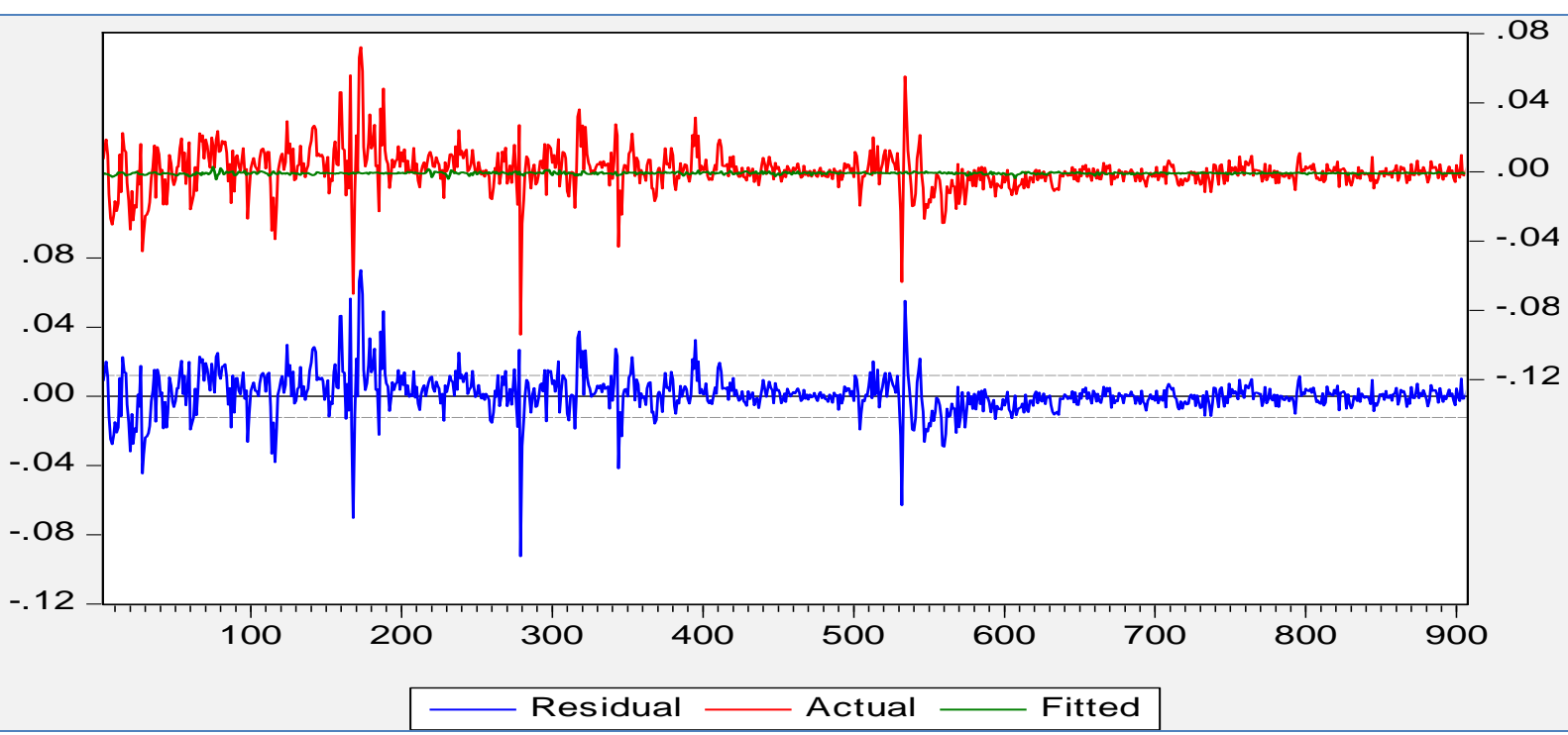

Figure 02: Volatility of COBEX

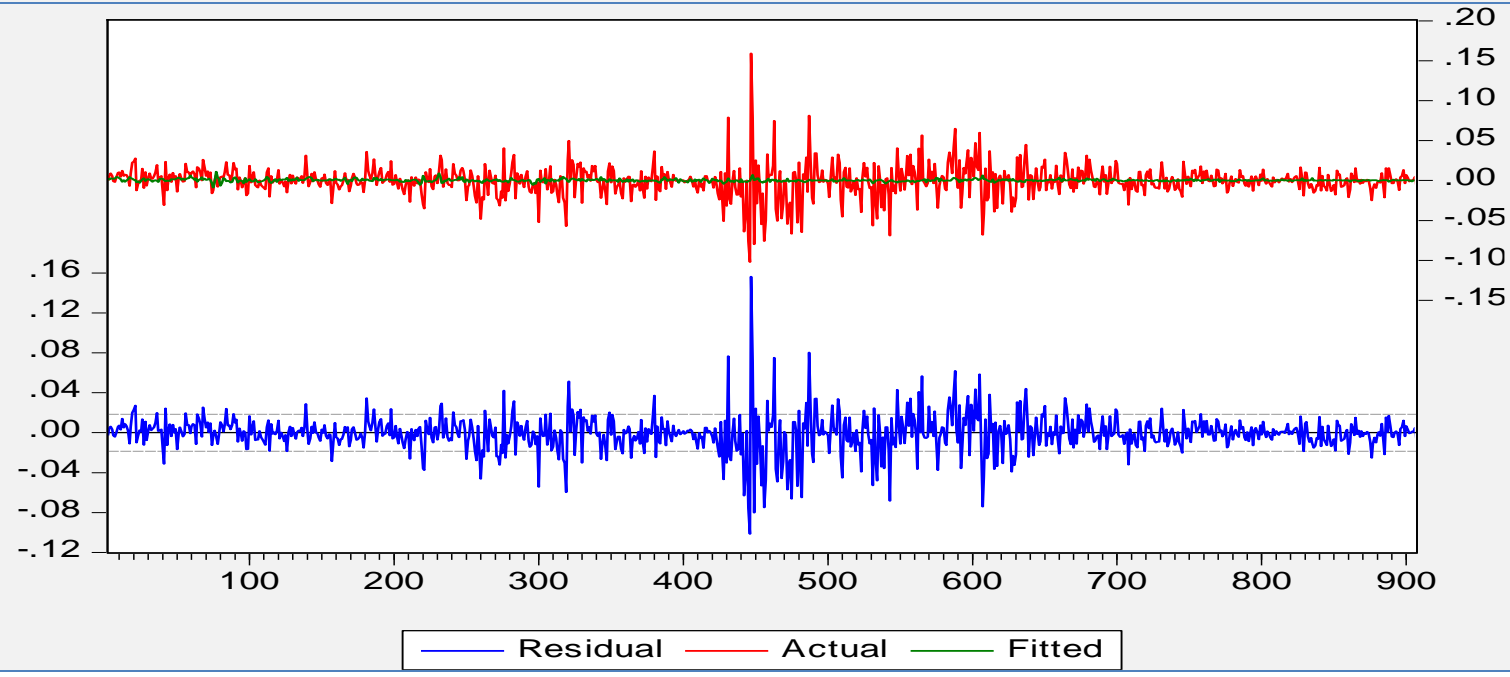

Among the three stock markets in transition, CROBEX has the lowest volatility features during the financial crises free period and moderate volatility in the latest financial crises as shown in Fig.2. After crises, all three stock markets enjoy low and stable volatility.

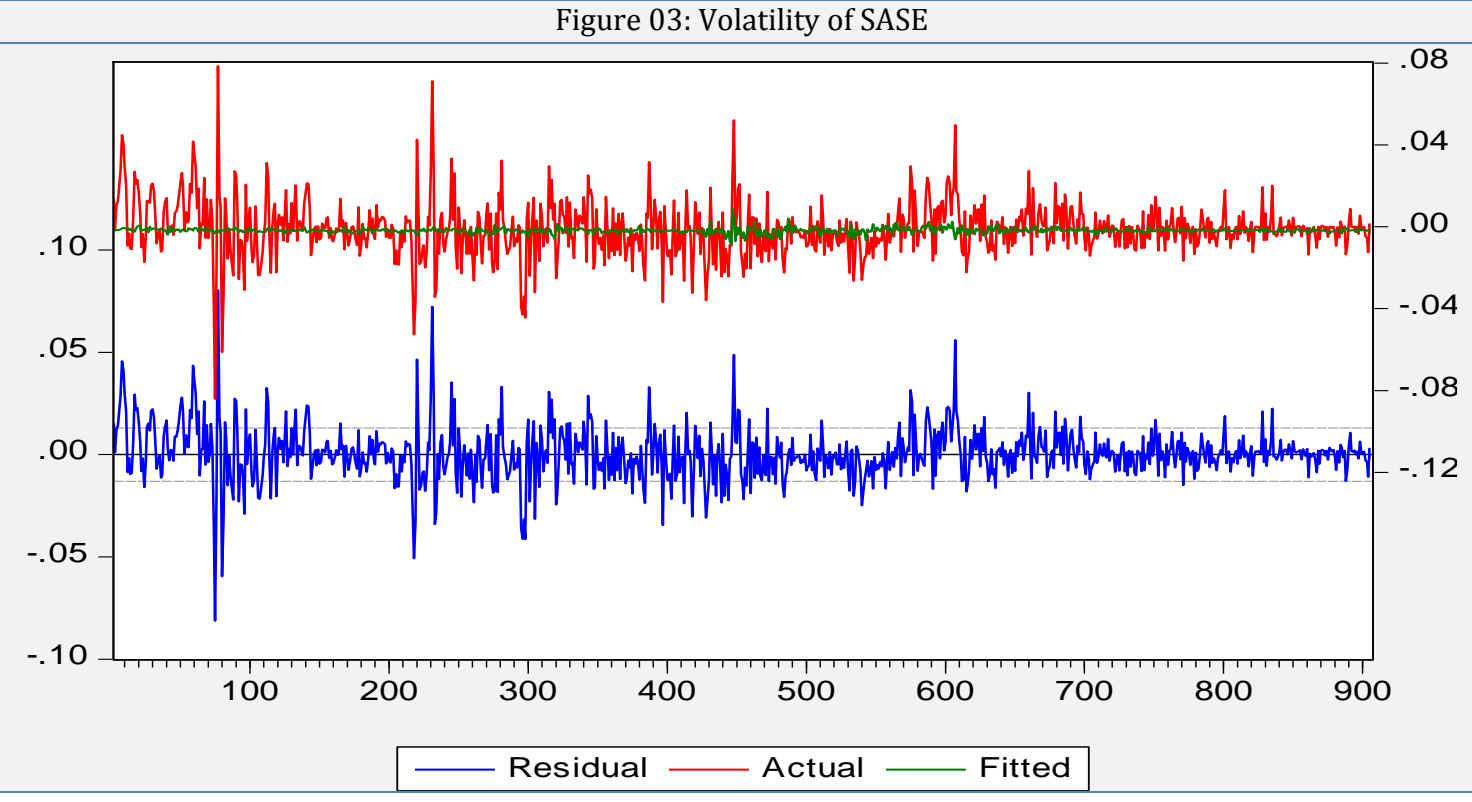

The last large financial crisis began in 2007, reached the bottom in 2008, and is still present. After applying the ARCH modeling to the equity returns data collected for the period of 2007-2010 in several markets of interest for the article, it can be stated that although due to the globalization effect, in which it is expected that stock markets 
show uniform responses to financial crashes, the degree of stock market volatility differs from one region to another, depending on the level of integration with the international economy. Observing stock markets of the neighbor countries of Bosnia and Herzegovina, Croatia and Serbia, we can see uneven developments and different responses to the emerging financial crisis.

\subsection{Conclusion}

This study explores the volatility spillover among the three stock markets of Balkan countries in transition which are Croatia, Bosnia and Herzegovina and Serbia. Given that the globalization has integrated financial markets, the hypothesis is that the emerging financial crisis has affected all stock markets worldwide to some degree, although shock sensitivity is significantly more obvious in emerging countries. Result from the GARCH (1.1) model implies that only Serbian stock market volatility is being influenced by the Bosnia and Herzegovina and Croatia.

Lack of external volatility transmission to Bosnian and Croatian stock markets form the other two former Yugoslavian countries are observed. Additionally all three-stock market's volatility is being influenced by its own shocks and information channels. Bosnian and Croatian stock markets have higher volatility features compared to Serbian stock market. All three stock markets show stable low volatility after latest financial crises. Our results have implications for international portfolio investors which are looking for diversified markets.

\section{References}

Bessler, D. A., and Yang, J. 2003. The structure of interdependence in international stockmarkets. Journal of International Money and Finance, 22:261-287

Bollerslev, T. 1986. Generalized autoregressive conditional heteroskedasticity. Journal of Econometrics, 31(03):307-327.

Chaudhuri, K., and Wu, Y. 2003. Random walk versus breaking trend in stockprices: evidence from emerging markets. Journal of Banking \& Finance 27(4):575-592.

Engle, R. F. 1982. Autoregressive conditional heteroskedasticity with estimates of the variance of U.K. inflation. Econometrica 50(4):987-1007.

Ercan, H., Taymaz, E., \&Yeldan, E., 2010. Crisis and Turkey: Impact analysis of crisis response measures. International Labor Organization, 9-15.

Kaminsky, G., \& Schmukler, S. L. 2002. Emerging markets instability: Do sovereign ratings affect country risk and stock returns. World Bank Economic Review 16(2):171-195.

Nikkinen, J., Omran, M. M., Sahlström, P., \&Äijö, J. 2008. Stock Returns and Volatility Following the September 11 Attacks: Evidence from 53 Equity Markets. Int. Review of Financial Analysis 17:27-46.

Phylaktis, K., and Ravazzolo, F. 2002. Measuring financial and economic integration with equity prices in emerging markets. Journal of International Money and Finance 21(6):879-903.

Ratanapakorn, O., \& Sharma, S.C., 2002. Interrelationships among regional stock indices. Review of Financial Economics 11(2):91-108.

Roll, R., 1988. The international crash of October 1987.Financial Analysts' Journal 44(5):19-35.

Saez, L. C., Fratzscher, M., \&Thimann, C. 2009. The transmission of emerging market shocks to global equity markets. Journal of Empirical Finance, 16:2-17.

Samarakoon, L. P., 2011. Stock market interdependencies, contagion, and the US financial crisis: The case of emerging and frontiermarkets. International Financial Markets, Institutions and Money 21(5):724-742.

Samitas, A., Kenourgios, D., \&Paltalidis, N. 2007.Integration and behavioral patterns in emerging Balkan stock markets.Working paper, EFMA Annual Conference, 5-20.

Swanson, P.E., 2003. The interrelatedness of global equity markets, money markets, and foreign exchange markets. International Review of Financial Analysis 12(2):135-155.

Syriopoulos, T., 2004. International portfolio diversification to central European stock markets. Applied Financial Economics, Taylor and Francis Journals 14(17):1253-1268.

Syriopoulos, T., 2007. Dynamic linkages between emerging European and developed stock markets: Has the EMU any impact? International Review of Financial Analysis 16(1):41-60.

Uygur, E., 2010. The global crisis and the Turkish economy. Third World Network, 131:15-17.

Wong, A. S. K., and Vlaar, P. J. G., 2003.Modelling time-varying correlations of financial markets. WO Research Memorandum, no. 739: 16.

Yang, J., Hsiao, C., Li, Q., and Wang, Z., 2006. The emerging market crises and stock market linkages: further evidence. Journal of Applied Econometrics 21(6):727-744. 